ORIGINAL RESEARCH

\title{
Skin Diseases Affecting High-Level Competition Sailors: Descriptive Study Carried Out During the 2012 AG2R Transatlantic Boat Race
}

\author{
Brice Loddé, MD; Catherine Mahé, MD; Laure Jacolot, MD; Richard Pougnet, MD; David Lucas, MD; \\ Dominique Jegaden, MD; Jean-Dominique Dewitte, MD, PhD; Laurent Misery, MD, PhD; Ray Lucas, MD \\ From the Occupational and Environmental Diseases Department, (Drs Loddé, Pougnet, and Dewitte) and the Department of Dermatology and \\ Venereology, Brest University Hospital, Brest, France (Drs Mahé and Misery); the Finistère Sailing Centre, La Forêt-Fouesnant, France \\ (Dr Jacolot); the Department of Occupational Health in Iroise Brest, France (Drs D. Lucas and Jegaden); and the Department of Emergency \\ Medicine, George Washington University, Washington, DC, United States (Dr R. Lucas).
}

\begin{abstract}
Objectives. - The primary objective of this study was to identify skin disorders encountered in a population of sport sailors. Unlike merchant mariners and fishermen, there is sparse literature on this maritime population. Secondary objectives were to uncover on-board conditions that may contribute to dermatological problems in this population.

Methods.-We conducted a prospective study during the 2012 AG2R transatlantic race. Sixteen two-man crews participated in this race, all using the same model of sailboat (Bénéteau Figaro 2). Clinical examinations were conducted, photographs taken, and questionnaires containing 34 questions were handed out before departure and on arrival, 22 to 24 days later.

Results.-Twenty-eight of 32 skippers (88\%) participated in departure data collection, and 18 (56\%) completed data collection on arrival. The average age of sailors was 34 years $(\mathrm{SD}=8)$. Compared with skin diseases documented on departure, there was an increased amount of folliculitis on the buttocks, fungal infections, and hyperkeratosis of the hands on arrival. Furthermore, several new skin problems were found postrace: skin scaling, skin erosions on the buttocks, dyshidrosis, thermal burns, and sunburns. The use of protective gear and sunscreen was common, but on-board hygiene was poor with infrequent bathing and clothing changes.

Conclusions.-Skin conditions are nearly universal in this maritime population. Further assessments are needed to know if long-term use of protective gear; improved hygiene; use of barrier creams; and proper on-board care of fungal infections, wounds, and burns could reduce the number and severity of skin problems encountered in sport sailors.
\end{abstract}

Key words: sailor, dermatitis, maritime, sport, boat

\section{Introduction}

Skin disorders have been identified as a significant health issue in the marine environment, ${ }^{1,2}$ and in 1 study, ${ }^{2}$ skin disorders accounted for up to $10 \%$ of all cases requiring treatment by a maritime telemedicine service. Most of the published literature relates to occupational skin disorders in the merchant marine and the fishing industries. $^{3-5}$ However, professional yacht skippers who sail for sport may also be at risk for dermatologic

Corresponding author: Brice Loddé, MD, Brest University Hospital, Occupational and Environmental Diseases Department (Service de Santé au Travail et Maladies liées à l'environnement), 2 Avenue Foch, Brest Cedex 29609, France (e-mail: Brice.lodde@chu-brest.fr). conditions related to the marine environment. This recreational population would not be captured in the required occupational disease reporting mechanisms common in Europe and the United States. The existing literature on illness and injury in the professional recreational skipper is sparse and relies largely on selfreporting, which may underestimate the scope of the problem. $^{6-9}$ In 1 study, ${ }^{7}$ skin disorders accounted for $20 \%$ of all illnesses reported during a single ocean yacht race, suggesting the problem may be significant. There are no published studies solely focused on the incidence and type of skin disorders.

The aim of this study was to systematically identify all skin disorders affecting professional skippers in a single 
transatlantic yacht race. A secondary aim was to uncover environmental, on-board activity and individual factors that may contribute to the development of dermatologic conditions in this population.

\section{Methods}

This was an observational, descriptive study focusing on skin lesions of skippers taking part in the AG2R transatlantic boat race in 2012. ${ }^{10}$ The race covers 3890 nautical miles in open ocean from Concarneau, France to St. Barts, French West Indies (Figure 1). All boats in the race were identical Bénéteau Figaro 2 sailboats (Figures 2 and $3 \mathrm{a}$ and $\mathrm{b}$ ) with a two-man crew. ${ }^{11}$ The 11th edition of the race in 2012 had 32 participants, and all were approached for inclusion in the study. Approval by an institutional review board is not required in France for observational studies.
Three data sources were used for the study. First was a review of a general medical examination performed by a physician, which was required before participation in the race. Second was a race participant questionnaire administered before and after the race. The prerace questionnaire contained 30 questions related to general health and condition, prior and existing dermatological problems, and plans for skin care and hygiene on board during the race. The postrace questionnaire was shorter, with 9 questions focused on skin problems encountered during the race, how they were cared for on board, and perceived efficacy of any on-board treatment. Third, photographs were taken of each participant using the same high-definition camera focused on hands, elbows, knees, feet, and buttocks. Other areas were photographed only if there were skin problems or lesions reported in additional areas. Photographs were obtained before and after the race. All photographs

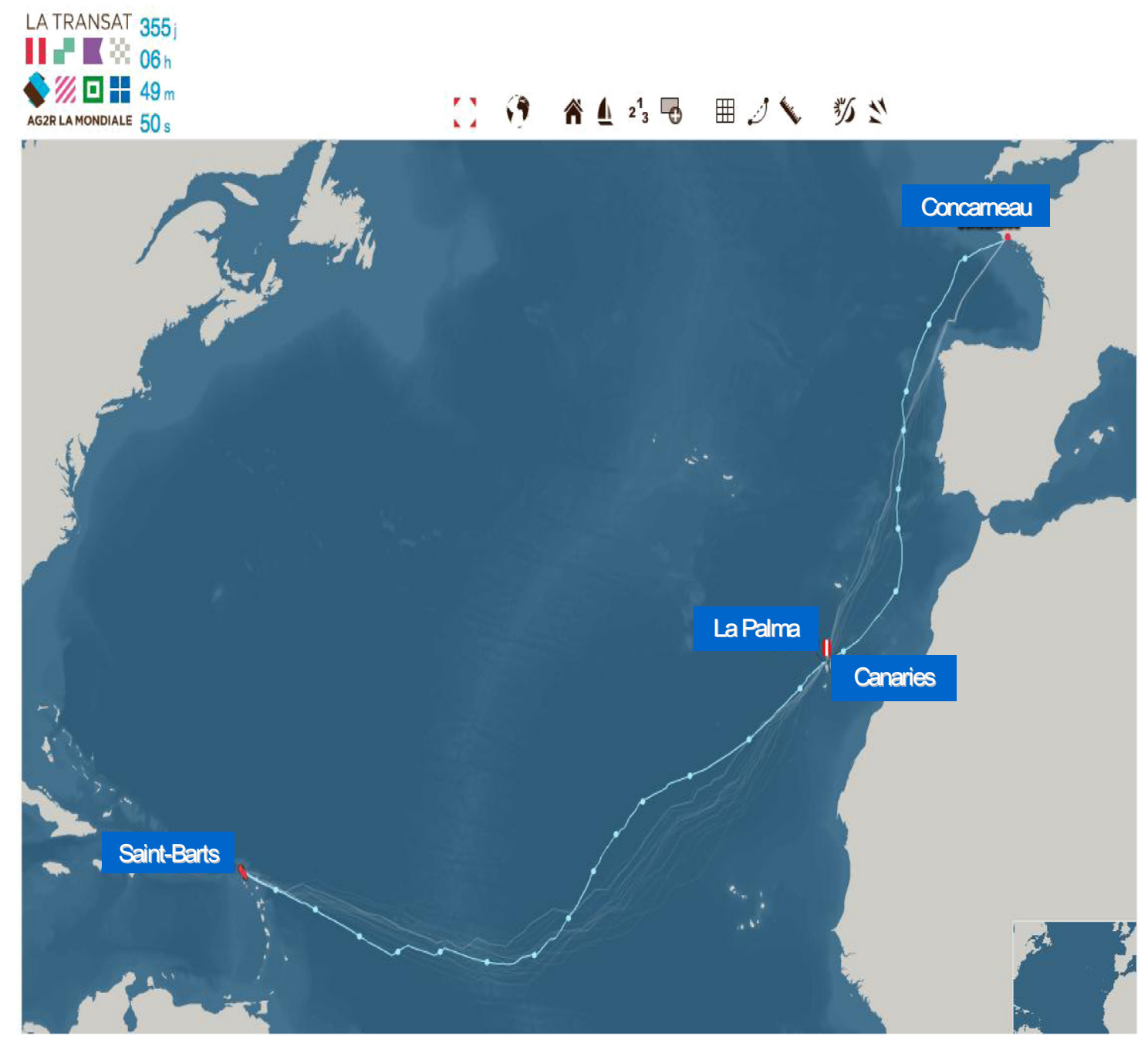

Figure 1. Map of race routes of 2012 AG2R transatlantic boat race. 


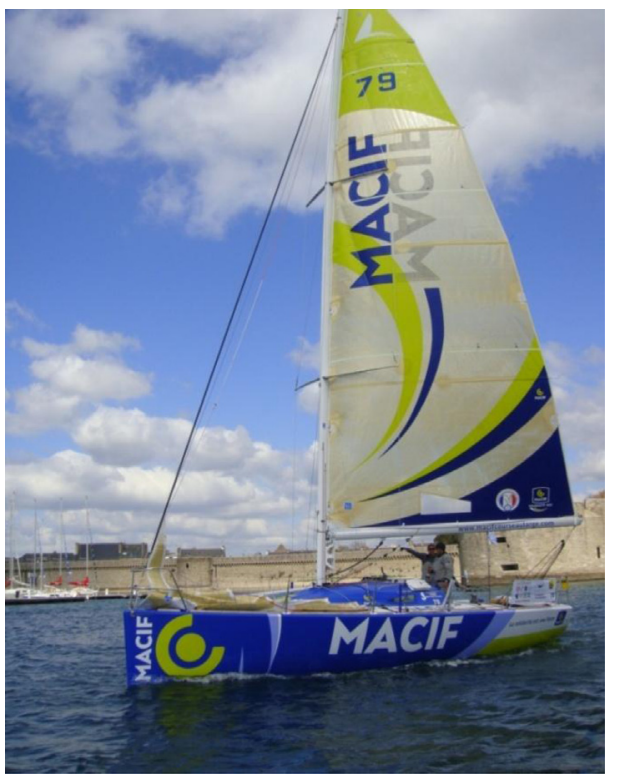

Overall length: $10.10 \mathrm{~m}$

Waterline length : $9.82 \mathrm{~m}$

Overall width : $3.46 \mathrm{~m}$

Maximum allowable draught: $2.10 \mathrm{~m}$

Displacement: $3050 \mathrm{~kg}$

Weigh of water ballast: $1100 \mathrm{~kg}$

Mainsail : $36 \mathrm{~m}^{2}$

Genoa : $30 \mathrm{~m}^{2}$

Spinnaker : $85 \mathrm{~m}^{2}$

Figure 2. Characteristics of the Bénéteau Figaro 2 boat.

were reviewed by a general medical doctor and secondarily reviewed by a dermatologist if a dermatologic diagnosis was made. The data from these 3 sources were collected by the authors and entered into an Excel spreadsheet. Most of the data were presented as mean \pm standard deviation.
A

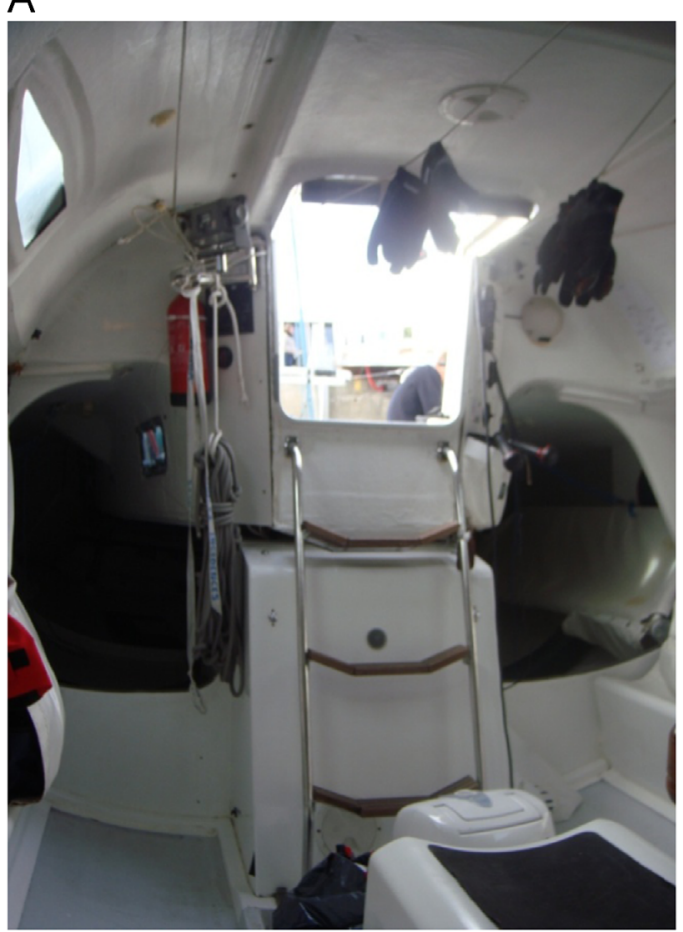

B

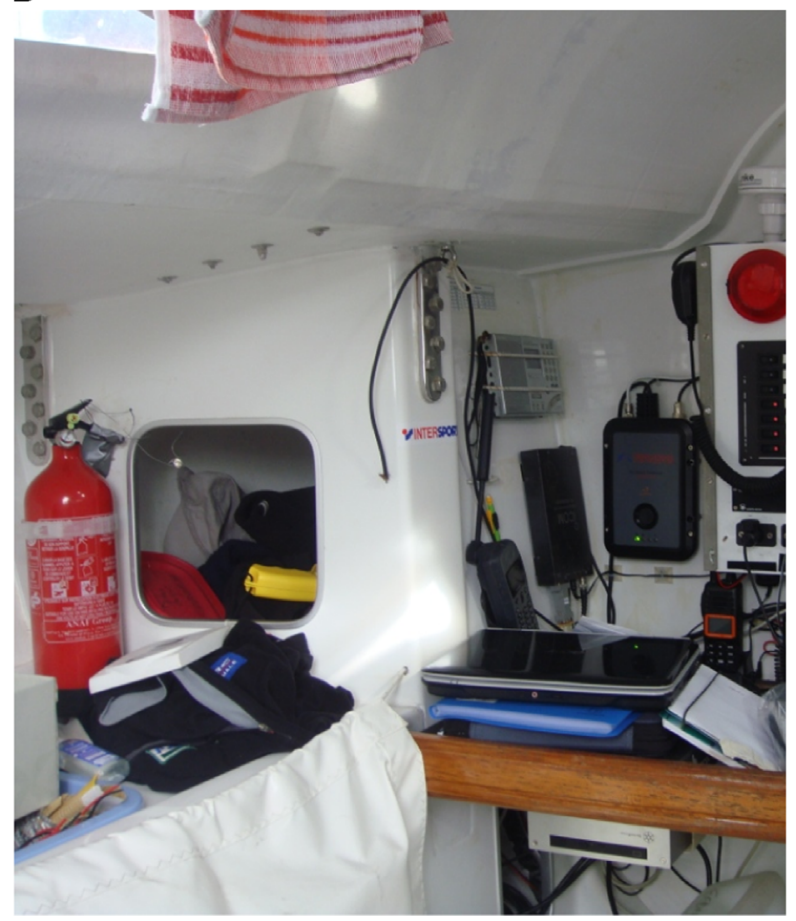

Figure 3. Inside the Bénéteau Figaro 2 boat. 
Table 1. Participation rate in the study

\begin{tabular}{lcc}
\hline & Departure & Arrival \\
\hline & 29 & 20 \\
Questionnaires & 28 & 18 \\
Photographs and medical examinations & & \\
\hline
\end{tabular}

Results

\section{RACE CONDITIONS}

The race lasted 22 days, and a variety of environmental conditions were encountered, including squalling rain showers and high winds with gusts up to 30 knots on the initial days of the race. This was followed by approximately 1 week of pleasant, dry weather. On day 13, high winds returned and rising temperatures were encountered as the crews entered the tropical latitudes. In the last 500 miles of the race, the crews were required to remove large amounts of seaweed from their boats for optimal sailing. The crews were exposed to a temperature range of $15^{\circ} \mathrm{C}$ to $30^{\circ} \mathrm{C}$, wet and dry conditions, and clothing ranging from rain gear to minimal coverage on hot, dry days.

\section{PARTICIPATION RATES}

All 32 skippers agreed to participate in the study. However, because of time constraints and a variety of competing tasks during race preparation and conclusion, we were unable to collect pre- and postquestionnaires and photographs from every participant. Table 1 describes the rate of completion for each data source.

\section{GENERAL HEALTH}

Overall, skippers were in good general health and physical condition. Three of the 32 skippers were women. Skippers ranged in age from 22 to 54 years, with an average age of $34( \pm 8)$ years. The average body mass index was $24.2( \pm 3.4) \mathrm{kg} / \mathrm{m}^{2}$. Seventy-two percent reported receiving regular medical care. Fifty-five percent were smokers. Sixty-five percent reported keeping to a year-long physical conditioning program with exercises such as running, weight lifting, abdominal exercise, swimming, and bicycle riding. Forty-eight percent reported special physical conditioning leading up to the race, concentrating on running, strength training, and swimming. A history of musculoskeletal problems was common, including cervical and lumbar pain and spinal disc disease. One skipper had hemochromatosis, and another had previously undergone a complete hip replacement.

\section{DERMATOLOGIC HEALTH}

Five of 29 skippers who completed the prerace questionnaire reported a history of skin diseases including fungal infections, skin cancers, eczema, and furunculosis. Twenty-four $(83 \%)$ reported skin problems related to prior boat races versus $4(14 \%)$ who did not; only 1 sailor did not answer this question. These skin problems included buttock irritation $(n=9)$, hand scaling $(n=5)$, sunburn $(\mathrm{n}=3)$, and other skin problems $(\mathrm{n}=5)$. Only $7 \%$ (2 sailors) reported having race performance compromised by these prior skin problems.

\section{POSTRACE DATA}

Twenty participants completed the postrace questionnaire. Of these, 9 (45\%) reported a general medical problem or injury. A telemedicine service was available to all race participants. ${ }^{12,13}$ This service was only accessed 9 times for the following reasons: skin wound $(n=1)$, sea sickness $(n=2)$, sun stroke $(n=1)$, headache $(n=1)$, sinusitis $(n=1)$, twisted ankle $(n=1)$, tracheitis $(\mathrm{n}=1)$, and tooth pulled out $(\mathrm{n}=1)$. Moreover, $19(95 \%)$ reported experiencing some skin problem during the race. One skipper had improvement of his known eczema during the race.

\section{PHOTOGRAPHIC DATA}

Twenty-eight skippers had photographs taken before the race. Of these, $83 \%$ had some sort of skin disorder identified on the prerace pictures, which are summarized in Figure 4A. On departure, the most common findings were xerosis (dry skin) of the hands, hyperkeratosis of the hands and feet, and tinea pedis.

Postrace photographs were obtained for 18 skippers, and skin disorders identified are summarized in Figure 4B. Scaling on the hands (on fingertips) (Figure 5) was identified in $100 \%(n=18 / 18)$ of postrace photos, compared with only $7 \%(n=2 / 28)$ in prerace photographs. Other conditions that increased in frequency were hyperkeratosis of the hands, found in $72 \%(\mathrm{n}=13 / 18)$ postrace versus $29 \%$ $(n=8 / 28)$ prerace. Folliculitis on the buttocks (Figure 6) affected $55 \%$ of the sailors participating in the postrace data collection $(n=10 / 18)$ compared with $4 \%$ prerace $(n=1 / 28)$. Several new skin disorders were identified that were not seen on any prerace photographs, including new fungal infections, skin erosions on the buttocks, dyshidrosis, thermal burns (because of hot water or hot devices used to cook or to prepare tea and coffee), and sunburns. Of note, photographs of the elbows and knees did not reveal significant skin problems in either the pre- or postrace photographs. 

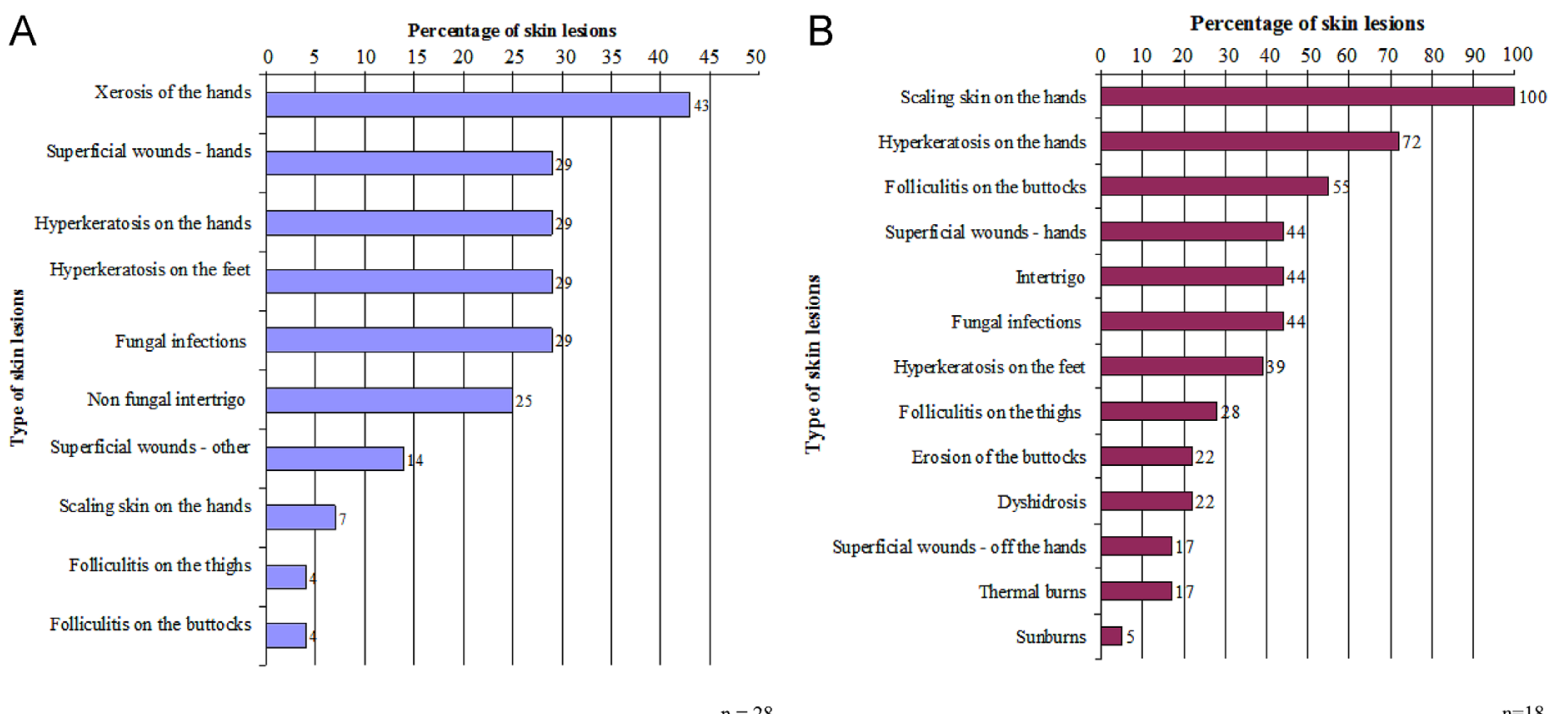

Figure 4. Photographic data about skin lesions on 28 sailors (a) before departure and on 18 sailors (b) on arrival of the 2012 AG2R race.

\section{SKIN CARE ON BOARD}

All skippers reported wearing protective gear such as rain jackets to adapt to environmental conditions. Most skippers $(76 \%)$ reported wearing gloves; however, the length of time they wore them was limited because of a belief that they retained moisture and encouraged maceration or scaling. All but 1 skipper reported using sun protection factor 50 sunscreen, which was available in the medication kit on all boats. Most skippers (86\%) reported not bathing daily during the race and wearing the same clothes for many days without changing; 2 to 7 (mean 5) days of wearing the same clothes were reported.

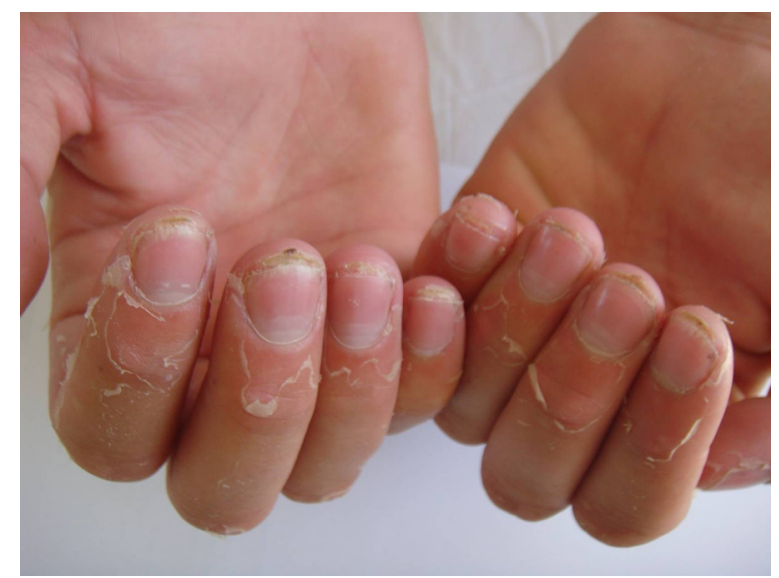

Figure 5. Postrace hand scaling.

\section{Discussion}

\section{COMPARISON OF DATA}

The current study reported a much higher incidence (95\%) of skin problems in yacht skippers than has been reported in other studies that cited incidences of $10 \%$ to $22 \%$.,14-19 $^{2,19}$ Skin problems in this population of athletes are generally not serious and often do not compromise race performance. Skin problems were likely underreported in other general studies of injuries and illness occurring during professional yacht racing. ${ }^{4,6-9}$ Moreover, this study was particularly focused on identifying skin problems, so it is not surprising that this targeted study reported a high incidence rate.

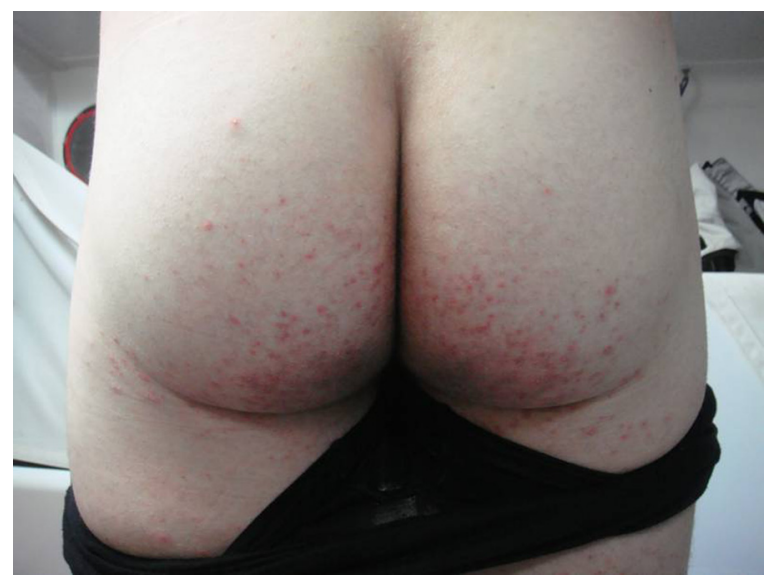

Figure 6. Folliculitis on the buttocks on arrival. 
Hyperkeratosis caused by chronic irritation, rubbing, or pressure ${ }^{4,20}$ was common on the hands and feet and markedly increased in the postrace photographs. The intensity of racing conditions (eg, the many repetitive movements associated with marine winch handling) combined with a lack of skin protection was likely contributory to this finding on hands. To prevent scaling of the hands, barrier creams in addition to gloves may be of benefit as a skin protectant. Skippers would need education regarding barrier cream use, and barrier cream should become standard in the on-board medical kit. ${ }^{21-23}$

Skin fungal infections were also common at baseline but were limited to the feet. On arrival, a number of fungal infections were identified in the groin and in skin folds not seen at baseline. The combination of skin breakdown from chronic rubbing or pressure and moist environments ${ }^{24}$ contributes to skin fungal infections. In 1 case in this study, a skipper self-treated tinea cruris with a corticosteroid cream, leading to worsening lesions. Skin fungal infections could be reduced by strategies to reduce exposure to moisture, such as frequent changing of the socks and underwear, receiving proper topical treatment on board, and accessing telemedical advice when needed. ${ }^{25}$

Folliculitis and irritation of the buttocks ${ }^{7}$ was a common finding in the postrace evaluation. Although this problem may be well known in the sailing community (and often referred to as "gunwale bum"), it is not widely reported in the medical literature, with the exception of an old publication. ${ }^{26}$ Spending too much time in wet clothing, experiencing friction on the skin from foul weather gear, and having general poor hygiene are likely contributors to this condition. Frequent clothing changes and barrier creams may be preventive. Early cases may be managed with topical antiseptics, and oral antibiotics may be required in severe cases. ${ }^{2}$

Traumatic skin lesions such as superficial wounds and thermal burns were collectively found in $50 \%$ of the skippers evaluated after the race. Although none were serious in this race, these types of injuries can cause significant disability and may become infected. Skippers should be educated in the proper care of traumatic wounds and burns, and medical kits should include topical antiseptics, topical antibiotics, and appropriate dressing material. ${ }^{21-23}$ Telemedical advice can help manage more serious cases. ${ }^{2,12,13,25}$

\section{LIMITATIONS}

This study has several limitations. The first is the small number of study subjects from a single race, which may limit the generalizability of our findings. Additionally, despite agreement by each skipper to participate in the study, data collection was incomplete because of race pressures and logistics. Furthermore, the departure and arrival data collection did not include the same subset of skippers, with some completing only the questionnaire or only the photographs on departure and arrival. This makes direct comparisons pre- and postrace difficult. Despite this limitation, we found several skin problems that were very common postrace and uncommon or absent prerace. Thus, we believe that these observations are important despite the study's limitations.

\section{Conclusion}

Skin disorders are a common medical problem encountered in professional open ocean sail races. Despite their near-universal nature, most skin problems encountered were not medically serious, and skin problems were never reported to affect skipper performance (although some sailors mentioned that prior races had been affected by skin problems) or to cause skippers to abandon the race. Nevertheless, in longer races, traumatic wounds and skin infections have the potential to become significant. Harsh environmental conditions, particularly dampness, combined with activities involving repetitive skin friction and poor skin hygiene are the fundamental causes of this problem. Hyperkeratosis, fungal infections, folliculitis, buttock irritation, and traumatic wounds are common.

Educating this population on proper skin care at sea is key to prevention, with emphasis on staying dry, changing clothing frequently, using protective gear, liberally applying barrier creams, and treating fungal and bacterial skin infections correctly and early. Consideration for dermatologic care should be part of the prerace medical screening, on-board medical supplies, and postrace care. Skin care is part of the overall medical support that should be provided to skippers, the final aim of which is to keep skippers healthy for optimal competitive performance.

\section{References}

1. Misery L. Maritime dermatology. Int Marit Health. 2008;59:113-115.

2. Lucas RL, Boniface K, Hite M. Skin disorders at sea. Int Marit Health. 2010;62:9-12.

3. Loddé B, Jegaden D, Dewitte JD. Occupational maritime skin diseases. Nouv Dermatol. 2004;23:458-464.

4. Arnault JP. Dermatological Pathologies of Sailors [thesis]. Nancy, France: Faculty of Medicine; 2008.

5. Loddé B, Roguedas AM. Dermatoses professionnelles. EMC-Dermatologie. 2014;9:1-14.

6. Neville VJ, Molloy J, Brooks JH. Epidemiology of injuries and illness in America's Cup yacht racing. $\mathrm{Br} J$ Sports Med. 2006;40:304-312. 
7. Price CJS, Spadling TJW, McKenzie C. Patterns of illness and injury encountered in amateur ocean yacht racing: an analysis of the British Telecom Round the World Race 1996-1997. Br J Sports Med. 2002;36:457-462.

8. Nathanson AT, Fisher EG, Mello MJ, Baird J. Injury and illness at the Newport-Bermuda race 1998- 2006. Wilderness Environ Med. 2008;19:129-132.

9. Nathanson AT, Baird J, Mello M. Sailing injury and illness: results of an online survey. Wilderness Environ Med. 2010;21:291-297.

10. La Transat AG2R La Mondiale. Available at: http://www. transat.ag2rlamondiale.fr/. Accessed October 2014.

11. Fédération Francaise de Voile. Available at: http://www. ffvoile.fr/ffv/web/. Accessed November 2014.

12. Guitton MJ. Telemedicine at sea and onshore: divergences and convergences. Int Marit Health. 2015;66:18-21.

13. Ricci G, Pirillo I, Rinuncini C, Amenta F. Medical assistance at the sea: legal and medico-legal problems. Int Marit Health. 2014;65:205-209.

14. Jolivet A. Collection of Data of Diseases of Skippers at Sea During Official Ocean Racing. Descriptive Study Using One Case [thesis]. Brest, France: University of Brest; 2010.

15. Dolivet G. Medical aspects of ocean sailing preparation of pleasure boat owners using personal experience. Th. Med. Brest, France 2008. Available at: http://www.medmer-for mation.com/bibliographie. Accessed November 2008.
16. Blondeau C. Sailing: An Analytical and Comparative Study of Accidents in Ocean Racing [thesis]. Marseilles, France: Faculty of Medicine; 1985.

17. Bardaille E. Medical Aspects of Ocean Racing [thesis]. Lille, France: Faculty of Medicine; 1988.

18. Shephard RJ. The biology and medicine of sailing. Sports Med. 1990;9:86-99.

19. Buchet C. Man, his health and the sea. Ahess. 1998;53: 343-345.

20. Perromat M, Chauve JY. Hands of single-handed round the world sailors. Nouv Dermatol. 2006;25:627-630.

21. Hadala M, Barrios C. Different strategies for sports injury prevention in an America's Cup yachting crew. Med Sci Sports Exerc. 2009;14:1587-1596.

22. Rouvillain JL, Mercky F, Lethuillier D. Injuries on offshore cruising sailboats: analysis for means of prevention. Br J Sports Med. 2008;42:202-206.

23. Legg SJ, Mackie HW. Change in knowledge and reported use of sport science by elite New Zealand Olympic class sailors. J Physiol Anthropol Appl Human Sci. 2000;19:83-92.

24. Tanzer J, Macdonald A, Schofield S. Infective skin conditions in an adult sea-going population. $J R \mathrm{Nav}$ Med Serv. 2014;100:47-55.

25. Dahl E. Briefing notes on maritime teledermatology. Int Marit Health. 2014;65:61-64.

26. Forsey R. The problem of sailor's skin. Can Med Assoc J. 1943;48:212-213. 